\title{
An Interesting Case of Autoimmune Liver Disease
}

\author{
Paras Kathuria ${ }^{1}$ Shilpa Arora ${ }^{1}$ Rahul Karna ${ }^{2}$ Naresh Kumar ${ }^{3} \quad$ Suresh Kumar ${ }^{3} \quad$ Premashis Kar $^{3, \odot}$
}

1Department of Medicine, Maulana Azad Medical College and Associated Lok Nayak Hospital, New Delhi, India

${ }^{2}$ Maulana Azad Medical College, New Delhi, India

${ }^{3}$ Maulana Azad Medical College and Associated Lok Nayak Hospital, New Delhi, India

Ann Natl Acad Med Sci (India):2021;57:62-64
Address for correspondence Premashis Kar, DM, PhD, E23 Nivedeta Kunj, Sector 10, R. K. Puram, New Delhi 110022, India (e-mail: premashishkar@gmail.com).

\begin{abstract}
Keywords

- autoimmune hepatitis

- cholestasis

- primary biliary cirrhosis

Autoimmune liver diseases (AILD) are part of a broad spectrum of liver diseases with autoimmune etiology, usually present individually but at times have overlapping features. We present the case of a 60 -year-old lady presenting with fatigue, itching and right upper quadrant abdominal pain. Further investigation showed cholestatic pattern of liver enzymes and evidence of portal hypertension without any evidence of extrahepatic obstruction. Autoimmune markers and liver biopsy showed overlapping features of both autoimmune hepatitis (AIH) and primary biliary cirrhosis (PBC), which is a separate diagnosis known as overlap syndrome, but by applying appropriate criterion, we were able to make a definite diagnosis of PBC. Differentiating PBC from overlap syndrome was important as therapy of both are different.
\end{abstract}

\section{Introduction}

Autoimmune liver diseases (AILD) are part of a spectrum of autoimmune diseases primarily involving the liver and includes autoimmune hepatitis (AIH), primary biliary cirrhosis (PBC), and primary sclerosing cholangitis (PSC). These diseases usually occur in isolation but sometimes their features may overlap, which is a distinct entity with different therapy known as overlap syndrome. Here, we present an atypical case of PBC with features of $\mathrm{AIH}$, thus presenting a diagnostic and therapeutic dilemma. It was important to differentiate PBC from overlap syndrome, as treatment of former focuses on ursodeoxycholic acid while latter needs steroids along with ursodeoxycholic acid. ${ }^{1}$

\section{Case Report}

A 60-year-old female who was a known case of type 2 diabetes mellitus (DM) and hypothyroidism presented to the clinic with complaints of easy fatiguability for 2 months, generalized itching for 1 month, and right hypochondriac pain for 15 days. She denied any history of fever, jaundice, or clay-colored stools. Physical examination

published online

December 30, 2020
DOI https://doi.org/

10.1055/s-0040-1722105 ISSN 0379-038X. revealed a nontender, firm liver with sharp regular margins palpable $6 \mathrm{~cm}$ below costal margin and a palpable spleen $2 \mathrm{~cm}$ below costal margin. There was no evidence of scleral icterus, ascites, or stigmata of chronic liver diseases. Initial laboratories showed hemoglobin $8.2 \mathrm{~g} \%$, total leukocyte count 8,400 cells $/ \mathrm{mL}$, platelet count 2 lacs $/ \mathrm{mL}$, liver function tests (LFT) revealed total bilirubin $0.8 \mathrm{mg}$ / $\mathrm{dL}$, aspartate aminotransferase (AST) levels $186 \mathrm{U} / \mathrm{l}$, alanine aminotransferase (ALT) levels $164 \mathrm{U} / \mathrm{L}$, alkaline phosphatase (ALP) $760 \mu / \mathrm{L}$, total protein $7.5 \mathrm{~g} / \mathrm{dL}$, albumin $2.5 \mathrm{~g} / \mathrm{dL}$, and prothrombin time (PT) 13 seconds. Ultrasonography showed liver span of $17 \mathrm{~cm}$ and heterogenous echotexture without any space-occupying lesion (SOL), portal vein diameter $12 \mathrm{~mm}$ with hepatopetal flow, normal common bile duct, gall bladder, and spleen $14 \mathrm{~cm}$ with normal echotexture without any SOL. Upper gastrointestinal (GI) endoscopy showed single column of grade 1 esophageal varices. Screening tests for hepatitis virus and human immunodeficiency virus were negative. Further laboratories showed thyroid-stimulating hormone (TSH) $60 \mu \mathrm{IU} / \mathrm{mL}$, antithyroid peroxidase $112.9 \mathrm{IU} / \mathrm{mL}$, positive antimitochondrial antibody (AMA) $(4+)$ and antiliver kidney microsome (1+), IgM levels $7.58 \mathrm{~g} / \mathrm{L}$, IgG levels $26.8 \mathrm{~g} / \mathrm{L}$ and negative

(c) 2020. National Academy of Medical Sciences (India).

This is an open access article published by Thieme under the terms of the Creative Commons Attribution-NonDerivative-NonCommercial-License, permitting copying and reproduction so long as the original work is given appropriate credit. Contents may not be used for commercial purposes, or adapted, remixed, transformed or built upon. (https://creativecommons.org/licenses/by-nc-nd/4.0/).

Thieme Medical and Scientific Publishers Pvt. Ltd. A-12, 2nd Floor, Sector 2, Noida-201301 UP, India 
antinuclear antibody, antismooth muscle actin, antisoluble liver antigen, antidouble stranded DNA, antitopoisomerase and anti- $\mathrm{U}_{1}$ ribonucleoprotein. Magnetic resonance cholangiopancreatography (MRCP) did not show any evidence of intrahepatic biliary radical dilation. Liver biopsy showed lobular architecture disarray with portal-to-portal bridging fibrosis, focal ballooning of hepatocytes, edematous expansion of portal tracts with moderate chronic inflammation and interface hepatitis, bile duct injury and bile ductular proliferation ( - Fig. 1). Copper-associated protein was present, indicative of chronic cholangiopathy. The overall picture presented a diagnostic dilemma for us. We initially made a diagnosis of AIH based on modified diagnostic criteria of the International Autoimmune Hepatitis Group, however, on using the extended criterion, that is, Revised Original Scoring System of the International Autoimmune Hepatitis Group, our patient falls in the probable diagnosis (10-15); for definite diagnosis $>15$ score is needed. ${ }^{2}$ Also the "Paris Criterion" used in various studies of overlap syndrome was not fulfilled in the case ( - Table 1 ). ${ }^{1}$ Hence, a final diagnosis of PBC was made and patient was started on $15 \mathrm{mg} / \mathrm{kg}$ UDCA and cholestyramine to which patient responded well both symptomatically and biochemically.

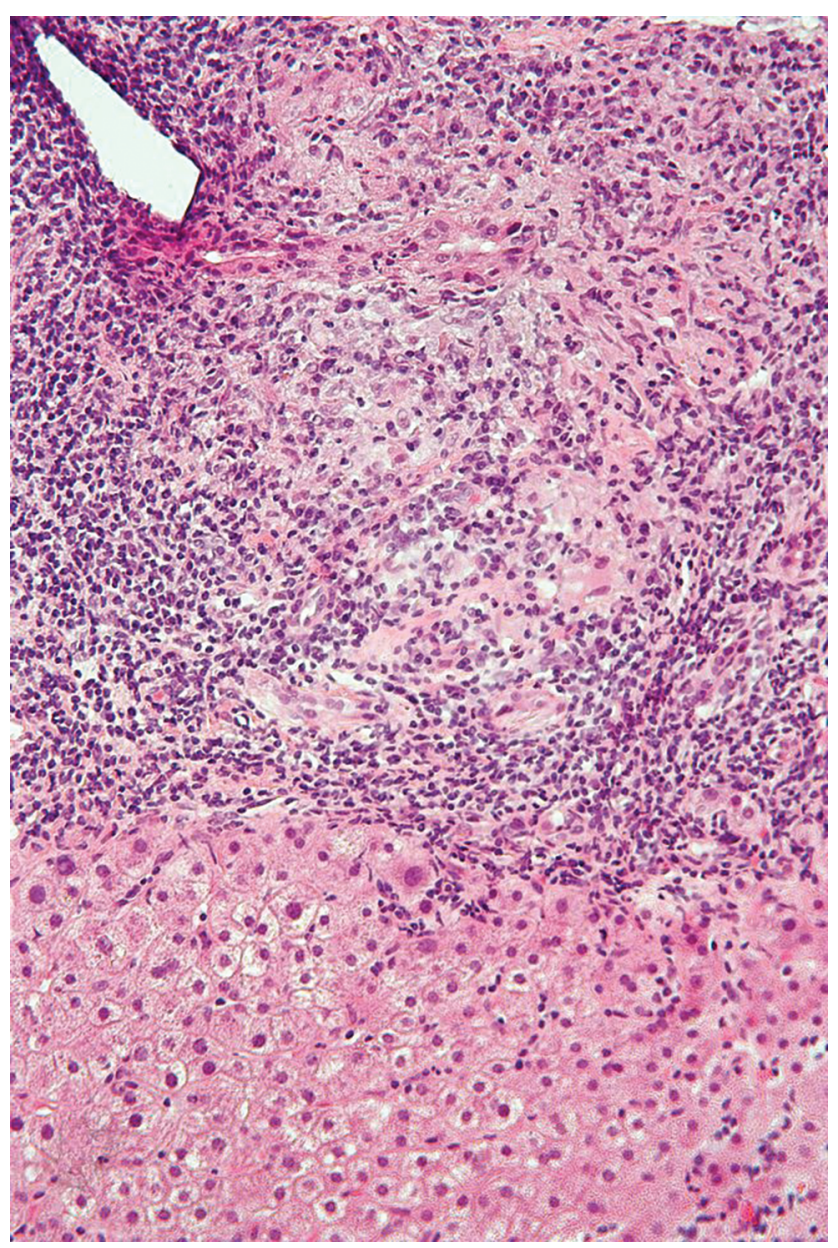

Fig. 1 High power (40x) view of hematoxylin and eosin-stained section of liver biopsy, showing interface hepatitis along with bile duct injury and proliferation.
Table 1 Paris criteria

\begin{tabular}{|l|l|}
\hline PBC criteria & AlH criteria \\
\hline $\begin{array}{l}\text { Serum ALP levels at least } \\
\text { two times the upper limit of } \\
\text { normal values or serum GGT } \\
\text { levels as least five times the } \\
\text { upper limit of normal values }\end{array}$ & $\begin{array}{l}\text { Serum ALT levels at least five } \\
\text { times the upper limit of normal } \\
\text { values }\end{array}$ \\
\hline A positive test for AMA & $\begin{array}{l}\text { Serum IgG levels at least two } \\
\text { times the upper limit of normal } \\
\text { values or a positive test for SMA }\end{array}$ \\
\hline $\begin{array}{l}\text { A liver biopsy specimen } \\
\text { showing florid bile duct } \\
\text { lesions }\end{array}$ & $\begin{array}{l}\text { A liver biopsy showing moderate } \\
\text { or severe periportal or periseptal } \\
\text { lymphocytic piecemeal necrosis }\end{array}$ \\
\hline
\end{tabular}

Abbreviations: AlH, autoimmune hepatitis; ALP, alkaline phosphatase; ALT, alanine aminotransferase; AMA, antimitochondrial antibody; GGT, gamma-glutamyl transferase; PBC, primary biliary cirrhosis; SMA, smooth muscle antibody.

Note: PBC-AIH overlap syndrome: 2 out of 3 criteria in each group are met either simultaneously or consecutively.

\section{Discussion}

$\mathrm{PBC}$ is an autoimmune disease of the liver involving intrahepatic ducts, leading to cholestatic manifestations, seen mainly in middle aged to elderly females. However, patients may also present late with features of cirrhosis and decompensation. ${ }^{3}$ Apart from historical pointers like pruritis, presence of easy fatigability is also a common feature (60-80\%). ${ }^{3}$ Biochemically, ALP is raised, although AST/ ALT may also be slightly increased. Bilirubin generally rises in advanced disease or after development of cirrhosis. ${ }^{4}$ The serological hallmark is the presence of AMA, which is seen in $95 \%$ of cases, although anti-PDCE2 or 2-oxo-glutaric acid dehydrogenase complex may also be seen. Liver biopsy is needed for assessing severity of disease or when there are certain atypical manifestations such as AMA-negative cases or raised AST/ALT. There is no definite treatment for PBC and patients are usually treated with ursodeoxycholic acid, which can slow down the course of the disease.

$\mathrm{AIH}$ is a chronic inflammatory disorder of liver usually affecting young females and presents with hepatocellular pattern of jaundice. Laboratory features reveal hypergammaglobinemia, presence of antibodies such as characterized by periportal inflammation, hypergammaglobulinemia, and circulating autoantibodies including antinuclear factor, antisoluble liver antigen and liver kidney microsomal antibody. Interface hepatitis is the hallmark feature of AIH and usually has a better prognosis, being responsive to steroid treatment. Sometimes, the clinical picture does not fit any of these and have overlapping features. Such a case is usually termed as overlap syndrome and can be seen in 3-7\% of patients with autoimmune liver disease (AILD). ${ }^{5}$ Recently, a case of overlap syndrome was reported by Bairy et al from south India, who was diagnosed on the basis of Paris criteria and treated with ursodeoxycholic acid. ${ }^{6}$ Rust et al reported another case of overlap syndrome treated with budesonide, ursodeoxycholic acid, and azathioprine. ${ }^{7}$ Differentiating overlap syndrome from $\mathrm{AIH}$ and $\mathrm{PBC}$ has therapeutic implications, as both ursodeoxycholic acid immunosuppression with steroids 
64 Autoimmune Liver Disease Kathuria et al.

would be required in patients with overlap syndrome. There are reports of beneficial effects of azathioprine and cyclosporine in corticosteroid-resistant patients with overlap syndrome..$^{8,9}$

In conclusion, overlap syndrome is an important differential to consider in patients with $\mathrm{PBC}$ showing features of $\mathrm{AIH}$. However, it is important to differentiate patients with $\mathrm{PBC}$ showing AIH features from those of overlap syndrome to prevent unnecessary steroids and other immunosuppressants exposure and side effects.

\section{Note}

Written informed consent was taken from the patient who participated in this study.

\section{Funding}

None.

\section{Conflict of Interest}

None declared.

\section{References}

1 Chazouillères $\mathrm{O}$, Wendum $\mathrm{D}$, Serfaty L, Montembault S, Rosmorduc O, Poupon R. Primary biliary cirrhosis-autoimmune hepatitis overlap syndrome: clinical features and response to therapy. Hepatology 1998;28(2):296-301

2 Alvarez F, Berg PA, Bianchi FB, et al. International Autoimmune Hepatitis Group Report: review of criteria for diagnosis of autoimmune hepatitis. J Hepatol 1999;31(5):929-938

3 Sarin SK, Monga R, Sandhu BS, Sharma BC, Sakhuja P, Malhotra V. Primary biliary cirrhosis in India. Hepatobiliary Pancreat Dis Int 2006;5(1):105-109

4 Amarapurkar DN, Patel ND. Spectrum of autoimmune liver diseases in western India. J Gastroenterol Hepatol 2007;22(12): 2112-2117

5 Czaja AJ. The overlap syndromes of autoimmune hepatitis. Dig Dis Sci 2013;58(2):326-343

6 Bairy I, Berwal A, Seshadri S. Autoimmune hepatitis - Primary biliary cirrhosis overlap syndrome. J Clin Diagn Res 2017;11(7): OD07-OD09

7 Rust C, Beuers U. Overlap syndromes among autoimmune liver diseases. World J Gastroenterol 2008;14(21):3368-3373

8 Chazouillères $\mathrm{O}$, Wendum D, Serfaty L, Rosmorduc O, Poupon R. Long term outcome and response to therapy of primary biliary cirrhosis-autoimmune hepatitis overlap syndrome. J Hepatol 2006;44(2):400-406

9 Duclos-Vallée JC, Hadengue A, Ganne-Carrié N, Robin E, Degott C, Erlinger S. Primary biliary cirrhosis-autoimmune hepatitis overlap syndrome. Corticoresistance and effective treatment by cyclosporine A. Dig Dis Sci 1995;40(5):1069-1073 